\title{
Türkiye'de Teşvik Uygulamalarının İstihdama Katkısı: Seçilmiş İller Üzerine Bir Panel Veri Analizi
}

\author{
Nihat Doğanalp* \\ ${ }^{1}$ Selçuk Üniversitesi, Beyşehir Ali Akkanat İşletme Fakültesi, İşletme Bölümü, Konya, Türkiye (ORCID: 0000-0003-4934-179X)
}

(Illk Geliş Tarihi 1 Aralık 2019 ve Kabul Tarihi 31 Aralık 2019)

(DOI: 10.31590/ejosat.659482)

ATIF/REFERENCE: Doğanalp, N. (2019). Türkiye'de Teşvik Uygulamalarının İstihdama Katkısı: Seçilmiş İller Üzerine Bir Panel Veri Analizi. Avrupa Bilim ve Teknoloji Dergisi, (17), 1285-1293.

\begin{abstract}
$\ddot{O} \mathbf{z}$
Yatırım teşvikleri, devlet tarafından istihdam, yatırım ve üretimde artı̧̧ sağlamak amacıyla kamu ve özel sektöre uygulanan destekler olarak nitelendirilmektedir. Cumhuriyetin ilanından günümüze kadar yatırım teşvik sistemleri yatırım ortamının şekillendirilmesi açısından sanayileşme ve istihdam politikalarının en önemli araçlarından birisi olmuştur. Zamanla ekonomik hayatın dinamik yapısı ile toplumun ihtiyaçlarının çeşitlenmesi bu ihtiyaçların kamu tarafından karşılanması ihtiyacını doğurmuştur. Bu çerçevede devletlerin ekonomik hayattaki varlığı ve ekonomik hayata müdahalesi hemen hemen tüm ülkelerde maliye politikası araçları vasıtasıyla gerçekleştirilmiştir. Bir maliye politikası aracı olarak teşvik politikaları da ekonomik kalkınma ve toplumsal refah açısından hükümetlerin sıklıkla başvurduğu araçlar olmuşlardır. 2012 yılında uygulamaya geçirilen yeni teşvik sisteminin en temel hedeflerinden birisi yeni istihdam olanakları oluşturmaktır.

Bu çalışmanın temel amacı nüfus bakımından Türkiye'de ilk 7 sırada bulunan illerin teşvik belgeli yatırımlarının istihdam üzerindeki etkilerini ortaya koymaktır. Bu kapsamda İstanbul, Ankara, İzmir, Adana, Bursa, Antalya ve Konya illerinde teşvik belgeli yatırım tutarlarının istihdam üzerindeki etkisi panel veri analizi yardımıyla incelenmiştir. Analiz sonuçlarında ilgili illerde yapılacak teşvik başvurusu sayısında 1 birimlik artış olması yaklaşık 25 yeni istihdam olanağının doğması, sabit yatırımlarda meydana gelecek 100 milyonluk bir artış da 26 kişiye yeni istihdam olanağı oluşturması anlamına gelmektedir.
\end{abstract}

Anahtar Kelimeler: Yatırım Teşvikleri, Teşvik Politikası, İstihdam

\section{Employment Contribution of Incentive Implementation in Turkey: A Panel Data Analysis on Selected Cities}

\begin{abstract}
Investment incentives are defined as subsidies applied to the public and private sectors by the government in order to increase employment, investment and production. Since the proclamation of the Republic, investment incentive systems have been one of the most important tools of industrialization and employment policies in terms of shaping the investment environment. In time, the dynamic structure of the economic life and the diversification of the needs of the society created the need to meet these needs by the public. In this context, the existence of states in the economic life and the intervention in the economic life has been realized in almost all countries through the means of fiscal policy. As an instrument of fiscal policy, incentive policies have been the tools frequently used by governments in terms of economic development and social welfare. One of the main objectives of the new incentive system introduced in 2012 is to create new employment opportunities.

The main objective of the study population in terms of investment incentive certificates of the provinces in Turkey in the first seven to reveal their impact on employment. In this context, the effect of investment incentives with investment incentives in Istanbul, Ankara, Izmir, Adana, Bursa, Antalya and Konya on employment was examined with the help of panel data analysis. According to the results of the analysis, an increase of 1 unit in the number of incentive applications to be made in the related provinces means that approximately 25 new employment opportunities will be created and an increase of 100 million in fixed investments will create 26 new employment opportunities.
\end{abstract}

* Dr. Öğr. Üy., Selçuk Üniversitesi, Beyşehir Ali Akkanat İşletme Fakültesi, Beyşehir-Konya, Türkiye, ORCID: 0000-0003-4934-179X, ndoganalp@selcuk.edu.tr 
Keywords: Investment Incentives, Incentive Policies, Employment.

\section{Giriş}

Günümüzde gelişmişlik düzeyi ne olursa olsun hemen hemen her ülkede bölgesel kalkınmaya yönelik olarak farklı politikalar uygulanmaktadır. Teşvik uygulamaları ilgili politikaların en önemli araçlarından biridir. Dünyada yaşanan değişimlere ayak uydurabilen ve hemen sürece entegre olabilen bir teşvik sistemi gelişmekte olan ülkelerde bölgesel kalkınma bakımından büyük öneme sahiptir. Ekonomik kalkınma teşvikleri bireysel işletmeler yönelik olarak uygulanan vergi iadeleri veya vergisel bazı avantajlar ekseninde uygulanabilen bir dizi uygulamayı kapsar. Hükümetlerin teşvikler ile ulaşmaya çalıştıkları temel hedef ekonomik kalkınma ekseninde büyümeye ve istihdama katkı sağlamaktır. Planlı kalkınma döneminin başlangıcından bu yana Türkiye'deki süreç incelendiğinde, ekonomik gelişmişlik düzeyini artırmak maksadıyla bazı faaliyetlerin teşvik edildiği gözlenmektedir. Bölgeler arası sosyo-ekonomik gelişmişlik farklarının önemli düzeylere ulaştı̆̆ı Türkiye'de sektörel bazda öngörülen genel teşviklerin yanı sıra bazı yöreler için teşvik tedbirlerinin daha da avantajlı hale getirildiği gözlenmektedir.

Yaşanan değişmeler ve sektörel açıdan stratejik adımlar atılması ihtiyacı yeni bir teşvik sisteminin geliştirilmesi ihtiyacını doğurmuştur. Bu çerçevede Bakanlar Kurulu'nun 2012/3305 sayılı Kararı ile yürürlüğe konulan Yeni Teşvik Sistemi (YTS) ile önceki sistemden farklı olarak, bir takım yeni düzenlemelere gidildiği görülmektedir. Yeni Teşvik Sistemi ile stratejik yatırımlar kavramına vurgu yapılarak yeni bir bölgesel harita ihdas edilmiş ve illerin sosyo-ekonomik gelişmişlik düzeyi esas alınarak, daha önce "4" olan bölge sayısı " 6 "ya çıkarılmıştır. Bununla birlikte yeni teşvik sistemi ile il bazlı bölgesel teşvik sistemine geçilmiş diğer bir ifadeyle bölgesel teşviklerden yararlandırılacak yatırım konuları, sektörel olarak, il bazında yeniden belirlenmiştir. Diğer taraftan büyük ölçekli yatırım kapsamında desteklenecek faaliyetlerin minimum yatırım tutarları düşürülmek suretiyle, büyük yatırımların sayıca arttırılması amaçlanmıştır.

Türkiye nüfusunun büyük bir kısmını barındıran illerde uygulanan teşviklerin istihdam üzerindeki etkisi son derece önem arz etmektedir. Bu çalışmanın temel amacı Türkiye'de uygulanan teşvik politikaları ekseninde seçilmiş iller bazında teşvikli yatırımların istihdam üzerindeki etkisini ortaya koymaktır.

\section{Teșvik Kavramı}

Teşvik kavramı isteklendirme, özendirme gibi anlamları içermektedir. Yatırım teşvikleri ise, genelde hükümetler vasıtasıyla seçilmiş bölge veya sektörlere yönelik yatırım yapılması amacıyla bu alanlarda sağlanan ölçülebilir avantajlar olarak tanımlanmaktadır. Bu avantajlar genel itibariyle yatırımcının kârını artırmaya veya yatırımcıların maliyet ve risklerini azaltmaya yönelik teşvikleri kapsamaktadır (UNCTAD, 2000: 11).

Genel anlamda teşvikler ile ilgili bir sınıflandırma Tablo-1'de sunulmuştur.

Tablo 1: Teşvik Türleri

\begin{tabular}{|l|l|}
\hline Teşvik Türü & Tanım ve Kapsamı \\
\hline Ekonomik teşvikler & $\begin{array}{l}\text { Düşük faizli kredi, enerji ve hammaddenin düşük fiyatla } \\
\text { temini ve insan kaynaklarının geliştirilmesine yönelik } \\
\text { faaliyetler gibi uygulamalardan oluşup daha çok } \\
\text { desteklenen ekonomik faaliyetlerin maliyetini azaltıp } \\
\text { kârlılığını arttırmaya yönelik sağlanan teşvik } \\
\text { uygulamalarıdır }\end{array}$ \\
\hline Mali teşvikler & $\begin{array}{l}\text { Sübvansiyonlar, alt yapı yatırımları, vergi muafiyet ve } \\
\text { indirimleri, vergi iadesi gibi uygulamalar olup daha çok } \\
\text { kamu harcamaları ve vergisel teşvikler olarak ön plana } \\
\text { çkmaktadır. }\end{array}$ \\
\hline Ídari ve teknik teşvikler & $\begin{array}{l}\text { Üün tanıtımı maksadıyla açılan fuar, sergi, patent ve } \\
\text { lisans haklarının sağlanması, yetişmiş insan gücü } \\
\text { konusundaki yardımları kapsayan uygulamalar ise } \\
\text { olarak nitelendirilmektedir. Ar-Ge faaliyetlerinin } \\
\text { desteklenmesi, lisans ve know-how alma kolaylıkları, } \\
\text { yabancı teknik personel çalıştırma imkânı, verimliliği } \\
\text { özellikle de işgücü verimliliğini artırmaya yönelik } \\
\text { teşvikler de bu başlık altında değerlendirilebilmektedir. }\end{array}$ \\
\hline
\end{tabular}




\begin{tabular}{|l|l|}
\hline Spesifik teşvikler & $\begin{array}{l}\text { Spesifik bir alanın veya bir problemin çözümlenmesine } \\
\text { yönelik olarak uygulanan hem nakdi hem de nakdi } \\
\text { olmayan teşvikleri kapsamaktadır. Örneğin ihracata } \\
\text { yönelik uygulanan teşvikler spesifik teşvik kapsamında } \\
\text { değerlendirilebilmektedir }\end{array}$ \\
\hline Menfi teşvikler & $\begin{array}{l}\text { Emsallerine göre daha ağır vergilendirme, gelişim } \\
\text { olanaklarını kısıtlama, yürüttüğü faaliyetleri sıkı bir } \\
\text { denetim altında bulundurma gibi uygulamalar ise } \\
\text { kısıtlama olarak adlandırılmaktadır. }\end{array}$ \\
\hline
\end{tabular}

Kaynak: Durman ve Önder (2006); Çiloğlu (1996); Berberoğlugil (1994).

\subsection{Teşvik Uygulamalarının Amaçları}

Teşvik uygulamaları ile hükümetlerin ekonomik açıdan ulaşmak istedikleri temel hedef ilgili ülkenin izlediği iktisadi ve siyasal politikalar ile uyum çerçevesinde ekonominin geneli veya belli bir sektör üzerinde mevcut durumu daha da iyiye taşımaktır. Ekonomik ve sosyal sorunları çözmede mevcut iktisadi şartların iyileştirilmesine yönelik olarak uygulamada en temel kamusal müdahale araçlarından birisi devlet teşvikleri olup bu teşvikler paralelinde sosyal devlet anlayışı da gelişim göstermiş olmaktadır.

Tarihsel açıdan bakıldığında hükümetlerin ekonomik yönetime şekil vermek amacıyla teşvik araçlarını kullanmaları uzun bir geçmişe dayanmaktadır. Özellikle ekonomik krizlerden sonra meydana gelen olumsuzlukların giderilmesinde teşvik politikaları birçok ülkede önem arz eden politikalar arasında yer almaktadır. Ancak çoğu zaman teşvik uygulamalarına, ekonomik ve sosyal sorunların uzun vadeli çözümünden çok kısa vadede bu sorunların azaltılması amacıyla başvurulduğu gözlenmektedir. Teşvik politikaları, 21. yüzyılda gelişmiş dünya piyasalarıyla sağlıklı bir etkileşimde bulunabilme açısından Türkiye için de vazgeçilemeyen araçlardandır. Türkiye, bir taraftan piyasa ekonomisinin getirdiği yapısal sorunları çözüme kavuşturmak, ulusal refahını arttırmak, rekabetçi bir ekonomiye sahip olabilmek ve doğrudan yabancı sermaye pastasından pay alabilmek gibi amaçlar doğrultusunda teşvikleri kullanırken diğer taraftan da uluslararası örgütlerin özellikle Avrupa Birliği’nin- ilkeleri kapsamında sürekli mevcut uygulamalarını revize etmektedir (Akdeve ve Karagöl, 2013: 341).

Bu doğrultuda Türkiye teşvik sisteminde bazı yeniliklere gitmiştir. Türkiye'nin 2023 hedefleri doğrultusunda dünyada ilk on ekonomi arasında yer almak, kişi başına düşen milli gelir düzeyini 25 bin dolara çıkarmak ve ihracatın 500 milyar dolar seviyelerine çıkarılması amacıyla "Yeni Teşvik Sistemi" hazırlanmıştır. Bu amaçlara ulaşılabilmesi ancak devletin yapısal ve yasal anlamda sağlayacağı destekler ile mümkün olabilir. Yeni teşvik sisteminin hazırlanmasının birincil amaçlarından birisi de budur. Yeni teşvik sistemi kapsamında Türkiye'nin mevcut ekonomik yapısı dikkate alındığında konulan makroekonomik hedeflere ulaşılabilmesinin yapılması gereken mikro yenilikler temeline dayandığı ifade edilmektedir. Bu doğrultuda üretim ve istihdam düzeyinin artırılması, bölgesel gelişmişlik farklarının azaltılması yeni teşvik sisteminin temel mikro amaçları arasında sayılmaktadır (Akdeve ve Karagöl, 2013: 342).

Türkiye'nin 2023 hedefleri ile üretim ve ihracat odaklı büyüme stratejisi açısından büyük önem arz eden yeni yatırım teşvik programı, kalkınma planları ve yıllık programlarda düşünülen hedeflere uygun olarak:

- Tasarrufları, katma değeri yüksek yatırımlara yöneltmek,

- Üretimi ve istihdamı artırmak,

- Uluslararası rekabet gücünü arttıracak ve araştırma-geliştirme içeriği yüksek büyük ölçekli yatırımlar ile stratejik yatırımları özendirmek,

- Uluslararası doğrudan yatırımları arttırmak,

- Bölgesel gelişmişlik farklılıklarını azaltmak,

- Kümelenme ve çevre korumaya yönelik yatırımları özendirmek gibi amaçların gerçekleştirilmesi hedeflenmektedir (www.ekonomi.gov.tr).

\subsection{Teşvik Uygulamaları ve İstihdam}

Tüm ekonomilerin temel makroekonomik hedeflerinin başında işsizliğin azaltmak ve istihdam yaratmak gelmektedir. On işten dokuzunun özel sektör eliyle arz edildiği dikkate alındığında özel sektörün istihdam yaratmadaki rolü ve devletin özel sektör girişimcilerine uygun yatırım ortamı sağlamak, yeterli iş ortamı (decent job) oluşturmalarına zemin hazırlamak ve bu nitelikteki iş imkanlarının artması için engelleri ortadan kaldırma rolü de son derece önem arz etmektedir.

Pek çok ülkede olduğu gibi Türkiye'de teşvik uygulamaları vasıtasıyla işsizliği azaltmaya yönelik faaliyetler yürütülmektedir. Dünya Bankası'nın sınıflandırmasına göre ülkeler gelir düzeyleri dikkate alınarak alt, orta (alt orta, üst orta olarak ayrıca sınıflandırılır) ve üst gelir düzeyi olmak üzere üç ana kategoriye ayırmaktadır. Bu kapsamda, orta ve düşük gelirli ülkelerdeki işgücü politikaları için belirlenmiş üç ortak hedef:

- Kişilerin çalışması için uygun ortam sağlamak, onları teşvik etmek

- Yüksek kaliteli, düzgün işler yaratılmasını garanti altına almak

- $\quad$ Riskleri yönetmek ve işgücü piyasasındaki geçişleri kolaylaştırmak şeklinde sıralanabilir.

$\mathrm{Bu}$ hedeflere ulaşmada sağlam bir makroekonomik yapının yanı sıra kendi hesabına çalışanlara ve girişimci olmak isteyenlere doğrudan teşvikler sağlamak suretiyle destek olunması ile birlikte işsizlik ve gelir şokları gibi risklere yönelik önlemler alma boyutu 
da ön plana çıkmaktadır. İlaveten friksiyonel işsizliği azaltmaya yönelik olarak Aktif İşgücü Piyasası Politikaları (AİPP) ön plana çıkarılması gerekmektedir. Dünya Bankası'nın sınıflandırmasına göre üst orta gelir düzeyinde bulunan, yaşlanma eğiliminde olan ve kayıt dışılığın azaldığı bir ülke olarak nitelendirilen Türkiye için de yukarıda sayılan ortak amaçların geçerli olduğu söylenebilir. İşgücü piyasalarında belirlenen hedeflere ulaşmak için yüksek düzeylerde kamu harcaması yapılan OECD ülkelerinde AİPP kapsamında genel olarak kamu istihdam hizmetleri, meslek eğitimi, gençliğe yönelik önlem politikaları, istihdam teşvik politikaları ve engellilere yönelik tedbirler başlıkları altında çeşitli politikalar uygulanmaktadır.

Türkiye'de nüfusun büyük kısmını barındıran illerde teşvik başvurularının ve teşvikli yatırımların daha yüksek olduğu gözlenmektedir. Türkiye'de TÜiK' in bölgesel bazlı hesaplamalarına göre 2018 yılına ilişkin işsizlik oranlarının dağılımı Şekil-1'de sunulmuştur.

\section{Şekil 1: 2018 Yllı Bölgesel Düzeyde İsssizlik Oranları}

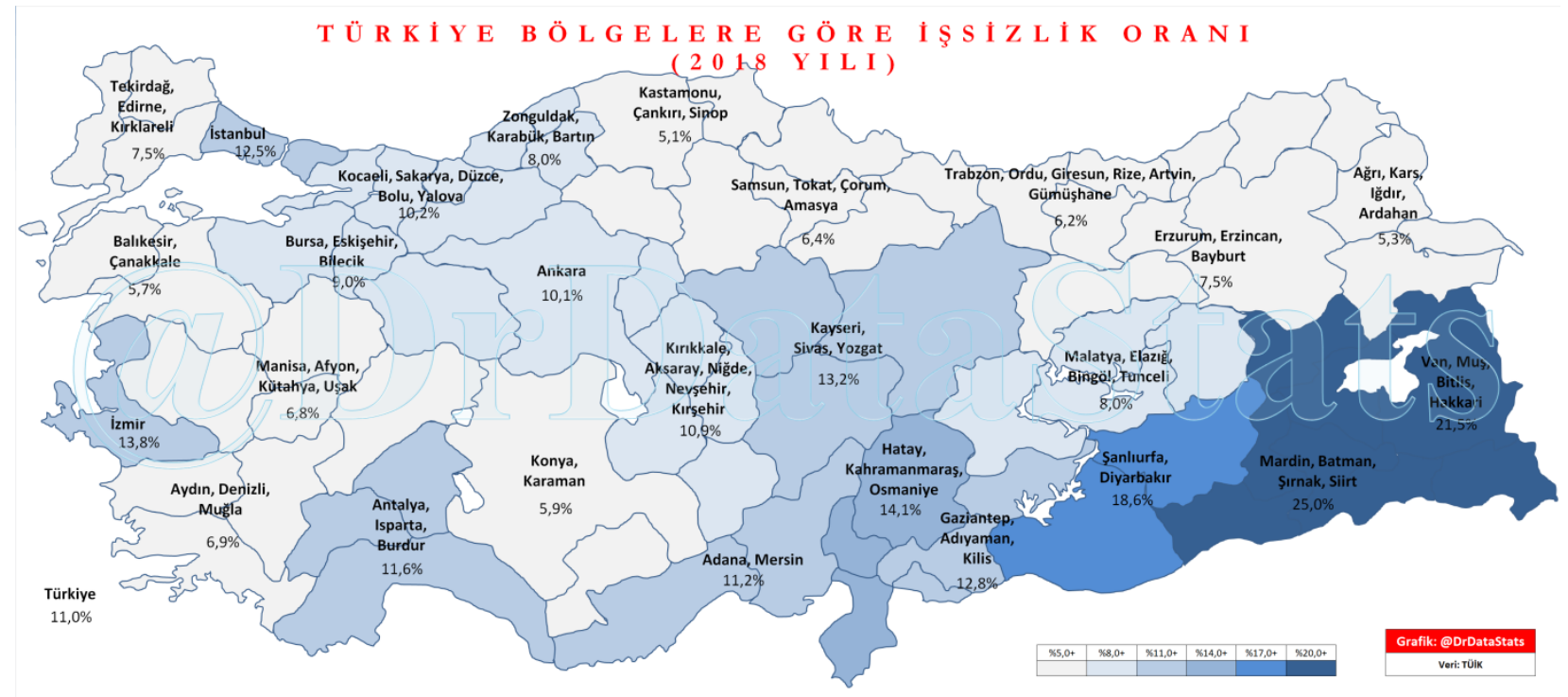

Kaynak: www.tuik.gov.tr

\section{Literatür}

Thomas (2000) ekonomik kalkınma teşviklerinin ABD eyaletlerinin ve belediyelerin iş yaratmalarına yardımcı olmak için kullanılan ve bütçeden yıllık 50 milyar dolardan fazla kaynak aktarıldığı yaygın bir politika aracı haline dönüştüğünü vurgulamaktadır. Her ne kadar teşviklerin nihai amacı yatıım hacmini ve istihdamı artırarak ekonomik kalkınmaya katkıda bulunmak olsa da literatürde yer alan bazı çalışmaların özellikle teşvik uygulamalarının etkisizliğine vurgu yaptığı görülmektedir.

Schalk ve Gerhard (2000) çalışmasında Batı Almanya'da bölgesel yatırım teşvikleri ile, bölgesel talep, büyüme ve kişi başına düşen gelir arasındaki ilişkiler incelenmiş ve diğer ülkelerde yapılan çalışmaların aksine Almanya'da bölgesel yatırım teşviklerinin istihdama olumlu etkilerinin olduğu sonucuna ulaşılmıştır.

James (2009) teşviklerin \%70' inin zaten yatırım yapacak veya genişletecek şirketlere tahsis edildiğini bundan dolayı teşvik uygulamalarının etkin olmadığını vurgulamaktadır.

Jensen vd. (2015), dünya genelinde teşvik programlarına ilişkin araştırmaları gözden geçirerek bu teşviklerin etkisizliğini ortaya koyan bir model geliştirmişlerdir.

Parilla ve Liu (2018) ABD’nin dört şehri üzerine yaptıkları teşviklerle ilgili inceleme sonucunda daha ekonomik ve titiz bir teşvik yaklaşımına doğru ilerleme gözlemlendiğini ve ekonomik kalkınmaya yönelik önemli ilerlemeler kat edildiğini ileri sürmektedirler.

\section{Metodoloji}

Panel veri analizi kesit ve zaman serilerinin bir arada kullanılmasına imkan tanıdığından hem değişken büyüklüğü hem de bu değişkenlerin seyrini bilmek açısından son derece önemlidir. Panel veri analizi ile amaçlanan bir diğer şey değişkenler arası değiş̧imi tanımlamak ve kestirim yapabilmektir (Hsiao, 2003: 89).

Kesit ve zaman serilerinin bir araya geldiği panel veri analizlerinde de değişkenlerin durağanlıkları ve uzun dönemde birlikte hareket edip etmedikleri incelemeye tabi tutulur. Bununla birlikte verilerin durağan olmaması halinde ortaya çıkabilecek sahte tahminler bertaraf edilmiş olur (Altunkaynak, 2007: 15).

Panel veri analizlerinde sıklıkla Sabit ve Rassal Etkiler Modeli çerçevesinde analizler yapılır. Bu modeller arasındaki ana farklılık sabit terimlerdir. Sabit etkiler modelinde her bir kesite ilişkin ayrı bir sabit terim bulunurken rassal etkiler modelinde birimlerin farklılıkları hata terimi yardımıyla modellenmektedir (Greene, 2010: 360). Sabit ve rassal etkiler modelinin her ikisinde de dışlanan etkileri modele dahil etmek mümkündür. 
Eğim katsayısının sabit olduğu ve sadece kesit veya zaman verisi ekseninde değişim gösteren modeller "sabit etkiler modeli" olarak anılırken birimlere ve zamana göre meydana gelen değişikliklerin modele bir hata terimi bileşeni olarak dahil edildiği modeller ise rassal etkiler modeli olarak adlandırılmaktadır (Baltagi, 1995: 13).

Rassal etkiler modeli, sadece kesit birim farklarını ele aldığında "Tek Yönlü Rassal Etkiler Modeli”, iki boyuta göre oluşan farkları ele aldığında ise "İki Yönlü Rassal Etkiler Modeli” şeklinde adlandırılmaktadır (Uğur, 2009: 57).

Tekyönlü bir rassal etkiler modeli:

$Y_{i t}=\beta_{0}+\beta X_{i t}+e_{i t}$ şeklinde yazılabilirken

İki yönlü bir rassal etkiler modeli:

Yit $=\beta_{0}+\mu i+\dddot{x}_{t}+\beta X_{i t}+v_{i t}$

$\mathrm{Bu}$ çalışmada kullanılan veri seti Teşvik Uygulama ve Yabancı Sermaye Genel Müdürlüğü'nün veri tabanından derlenmiştir. Çalışmada 2012(q1)-2019(q2) dönemine ait üçer aylık veriler kullanılmıştır. Analizlerde kullanılan değişkenlerin Tablo-2'de sunulmuștur.

Tablo 2: Analizlerde Kullanılan Değişkenler

\begin{tabular}{|l|l|}
\hline Değişken Sembolü & Değişken Adı \\
\hline EMP & İstihdam \\
\hline INCER & Teşvik Belgesi \\
\hline FIXIN & Teşvik Belgeli Sabit Yatırım Düzeyi \\
\hline
\end{tabular}

\section{Bulgular}

Analizlerde kullanılan değişkenlere ilişkin tanımlayıcı istatistikler tabloda sunulmuştur.

Tablo 3:Tanımlayıcı İstatistikler

\begin{tabular}{|l|c|c|c|}
\hline & EMP & INCER & FIXIN \\
\hline Ortalama & 2351.633 & 62.07619 & 1428.205 \\
\hline Medyan & 1654.500 & 51.00000 & 712.0000 \\
\hline Max & 16127.00 & 196.0000 & 20909.00 \\
\hline Min & 115.0000 & 10.00000 & 47.00000 \\
\hline Std. Hata & 2201.231 & 37.85308 & 2490.704 \\
\hline Skewness & 2.877842 & 1.159162 & 5.105242 \\
\hline Kurtosis & 15.16663 & 3.851035 & 34.15244 \\
\hline Jarque-Bera & 1585.104 & 53.36525 & 9403.875 \\
\hline Probability & 0.000000 & 0.000000 & 0.000000 \\
\hline Sum & 493843.0 & 13036.00 & 299923.0 \\
\hline Sum Sq. Dev. & $1.01 \mathrm{E}+09$ & 299466.8 & $1.30 \mathrm{E}+09$ \\
\hline Gözlem Sayis1 & 210 & 210 & 210 \\
\hline
\end{tabular}


Tablo 4: Panel Birim Kök Analizi

\begin{tabular}{|c|c|c|}
\hline & \multicolumn{2}{|c|}{ EMP } \\
\hline & \multicolumn{2}{|c|}{ Düzey I(0) } \\
\hline & t istatistiği & $p$ değeri \\
\hline Levin, Lin \& Chu t* & -7.85 & 0.0000 \\
\hline Im. Pesaran and Shin W-stat & -6.95 & 0.0000 \\
\hline ADF - Fisher Chi-square & 76,17 & 0.0000 \\
\hline \multirow[t]{4}{*}{ PP - Fisher Chi-square } & 87.86 & 0.0000 \\
\hline & \multicolumn{2}{|c|}{ INCER } \\
\hline & \multicolumn{2}{|c|}{ Düzey I $(0)$} \\
\hline & t istatistiği & $p$ değeri \\
\hline Levin. Lin \& Chu $t^{*}$ & -3.86 & 0.0001 \\
\hline Im. Pesaran and Shin W-stat & -3.22 & 0.0006 \\
\hline ADF - Fisher Chi-square & 32.71 & 0.0032 \\
\hline \multirow[t]{4}{*}{ PP - Fisher Chi-square } & 29.69 & 0.0084 \\
\hline & \multicolumn{2}{|c|}{ FIXIN } \\
\hline & \multicolumn{2}{|c|}{ Düzev I(0) } \\
\hline & tistatistiği & 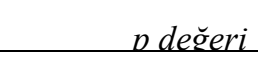 \\
\hline Levin, Lin \& Chu t* & -10.37 & 0.0000 \\
\hline Im. Pesaran and Shin W-stat & -8.46 & 0.0000 \\
\hline ADF - Fisher Chi-square & 96.44 & 0.0000 \\
\hline PP - Fisher Chi-square & 122.53 & 0.0000 \\
\hline
\end{tabular}

Tablo 4'te sunulan panel birim kök analizi sonuçlarına göre tüm değişkenlerin düzey değerlerinde durağan oldukları saptanmıştır.

Tablo 5: Panel Eşbütünleşme Testleri

\begin{tabular}{|c|c|c|}
\hline & \multicolumn{2}{|c|}{ Pedroni } \\
\hline & tistatistiği & $p$ değeri \\
\hline Panel v-Statistic & -0.93 & 0,8232 \\
\hline Panel rho-Statistic & -4.77 & 0,0000 \\
\hline Panel PP-Statistic & -8.61 & 0,0000 \\
\hline Panel ADF-Statistic & -8.34 & 0.0000 \\
\hline Group rho-Statistic & -4.83 & 0,0000 \\
\hline Groun PP-Statistic & -11.31 & 0.0000 \\
\hline \multirow[t]{3}{*}{ Groun ADF-Statistic } & -10.06 & 0.0000 \\
\hline & \multicolumn{2}{|c|}{ Kao } \\
\hline & t istatistiŏ $i$ & $p$ de ğeri \\
\hline $\mathrm{ADF}$ & -1.65 & 0,0496 \\
\hline Residual variance & 2153592 & \\
\hline HAC variance & 175762.3 & \\
\hline
\end{tabular}

Seriler arasında eşbtünleşme olup olmadığı Pedroni ve Kao testleri aracılığıla analiz edilmiştir. Bu çerçevede " $\mathrm{H}_{0}=$ Seriler arasında eş bütünleşme yoktur" hipotezi ekseninde Pedroni test sonuçlarına göre ilk istatistik dışında 6 istatistik değeri için sonuç anlamlı çıkmış ve $\mathrm{H}_{0}$ hipotezi reddedilmiştir. Bu kapsamda Pedroni sonuçlarına göre değişkenler arasında uzun dönemde birlikte hareket etme eğilimi olduğu gözlenmiştir. Benzer şekilde Kao test sonucu da \%5 anlam seviyesinde $(0,0496)$ anlamlı çikmış olup yine seriler arasında bir eş bütünleşme olduğuna işaret etmektedir. 
European Journal of Science and Technology

Sabit etkiler modeli çerçevesinde ulaşılan analiz sonuçları Tablo 6'da sunulmuştur.

Tablo 6: Sabit Etkiler Modeli

\begin{tabular}{|c|c|c|c|}
\hline Değișkenler & Katsayl & t istatistiği & p değeri \\
\hline C & 437,18 & 1,68 & 0,0936 \\
\hline INCER & 24,82 & 6,08 & 0,0000 \\
\hline FIXIN & 0,26 & 7,07 & 0,0000 \\
\hline R-squared & \multicolumn{3}{|c|}{0,71} \\
\hline Durbin-Watson stat & \multicolumn{3}{|c|}{62,64} \\
\hline F-statistic & \multicolumn{3}{|c}{0,0000} \\
\hline Prob(F-statistic) &
\end{tabular}

Tablo 6'dasunulan sonuçlara göre modelin anlamlılık düzeyi $\left(\mathrm{R}^{2}=0,71\right)$ olarak bulunmuştur. Bağımsız değişkenlerin bağımlı değişkeni açıklama gücü \%71'dir. Sabit etkiler modeli sonuçlarına göre teşvik belgesi sayısında yaşanacak bir birim artış istihdama yaklaşık 25 kişilik doğrudan katkıda bulunurken sabit yatırım düzeyinde yaşanacak bir birimlik artış kendisinin \%26'sı ekseninde istihdamı artırıcı etkide bulunmaktadır.

Rassal etkiler modeline göre analiz sonuçları Tablo7'de sunulmuştur.

Tablo 7: Rassal Etkiler Modeli

\begin{tabular}{|c|c|c|c|}
\hline Değiskenler & Katsavl & t istatistiği & p deăeri \\
\hline C & 198.81 & 0.62 & 0.5332 \\
\hline INCER & 28.63 & 7.88 & 0.0000 \\
\hline FIXIN & 0.26 & 7.11 & 0.0000 \\
\hline R-squared & \multicolumn{3}{|c|}{0.43} \\
\hline Durbin-Watson stat & \multicolumn{3}{|c|}{7.57} \\
\hline F-statistic & \multicolumn{3}{|c}{0.0000} \\
\hline Prob(F-statistic) &
\end{tabular}

Rassal etki modeli sonuçlarına göre de bağımsız değişkenlerin açıklayıcıllğı $\left(R^{2}\right) 0,43$ olarak hesaplanmıştır. Benzer şekilde teşvik belgesi başvurusunun artması istihdama yaklaşı 29 birim katkı sağlarken sabit yatırımların da istihdam üzerinde \%26'sı nispetinde etkisi olduğu görülmektedir.

Tablo 8: Hausman Testi Sonuçları

Correlated Random Effects - Hausman Test

Equation: Untitled

Test cross-section random effects

Test Summary

Chi-Sq. Statistic

Chi-Sq. d.f.

Prob.

Cross-section random

4.468904

2

0.1071

P olasılık değeri anlam düzeyi olan 0,05 ’ten büyük olduğu için $\mathrm{H}_{0}$ hipotezi reddedilir ve alternatif hipotez $\mathrm{H}_{1}$ kabul edilir. Bu da rassal etkiler modelinin daha uygun olduğu anlamına gelmektedir. 
Tablo 9: Panel Veri Analizi Sonuçları (Kukla Değişkenler Dahil)

\begin{tabular}{rrrrr} 
& Coefficient & Std. Error & t-Statistic & Prob. \\
\hline \hline C(1) & -161.7647 & 240.8378 & -0.671675 & 0.5026 \\
C(2) & 24.81565 & 4.081817 & 6.079560 & 0.0000 \\
C(3) & 0.261859 & 0.037061 & 7.065604 & 0.0000 \\
C(4) & 754.8427 & 350.8964 & 2.151184 & 0.0327 \\
C(5) & 1131.827 & 315.7577 & 3.584481 & 0.0004 \\
C(6) & 102.6072 & 339.8524 & 0.301917 & 0.7630 \\
C(7) & 2026.279 & 524.5410 & 3.862956 & 0.0002 \\
C(8) & 414.3422 & 342.0154 & 1.211472 & 0.2271 \\
C(9) & -237.2555 & 330.3599 & -0.718173 & 0.4735 \\
\hline \hline R-squared & 0.713576 & Mean dependent var & & 2351.633 \\
Adjusted R-squared & 0.702176 & S.D. dependent var & & 2201.231 \\
S.E. of regression & 1201.284 & Akaike info criterion & & 17.06208 \\
Sum squared resid & $2.90 \mathrm{E}+08$ & Schwarz criterion & & 17.20553 \\
Log likelihood & -1782.519 & Hannan-Quinn criter. & & 17.12007 \\
F-statistic & 62.59446 & Durbin-Watson stat & & 1.644305 \\
Prob(F-statistic) & 0.000000 & & \\
\hline \hline
\end{tabular}

6 kukla değişken dahil edilerek yapılan panel veri analizi sonuçları Tablo'da sunulmuştur. Bu sonuçlara göre bağımsız değiş̧kenlerin bağımlı değişkenleri açıklama düzeyi \%71'dir. F istatistiği değeri dikkate alındığında model bir bütün olarak anlamlıdır. Yapılacak teşvik başvurusu sayısında 1 birimlik artış olması yaklaşık 25 yeni istihdam olanağının doğmasına neden olmaktadır. Diğer taraftan sabit yatırımlarda meydana gelecek 100 milyonluk bir artış da 26 kişiye yeni istihdam olanağı oluşturma anlamına gelmektedir.

\section{Sonuç ve Değerlendirme}

Bir ülkede uygulanan ekonomik teşvikler o ülkenin izlemiş olduğu ekonomi, maliye ve sosyal politikalarıyla çok yakından ilgilidir. Teşvik uygulamaları ilgili politikalar açısından önemli bir araç niteliğindedir. Günümüzde çok geniş bir uygulama alanıyla karşımıza çıkan teşvikler özellikle bölgesel gelişmişlik farklarının arttığı, üretim, istihdam ve büyüme sorunlarının olduğu, işsizlik oranlarının ve dış ticaret açıklarının çoğaldığı kriz dönemlerinde krizlerin olası negatif etkilerini azaltmada önemli bir araç olarak kullanılabilmektedir. Bu yönüyle teşvik politikaları ekonomik krizlerle birlikte ortaya çıkan olumsuzlukların azaltılması ve ulusalbölgesel-yerel ölçekte sürdürülebilir kalkınmanın sağlanması açısından oldukça önemlidir.

Günümüzde teşviklerin büyük bir çeşitlilik göstermesinde ülkelerin ekonomik gelişmişlik seviyeleri, bölgelerarası gelişmişlik arasındaki fark, ülkelerin ekonomik, kültürel ve siyasi ilişkileri son derece etkilidir. Bu kapsamda teşvik uygulamaları genel ve bölgesel teşvik uygulamaları, büyük ölçekli yatırımların teşviki ve stratejik yatırımların teşviki şeklinde sınıflandırılabilmektedirler. Ekonomik teşviklerin ulusal, bölgesel ve yerel kalkınma açısından oldukça önem arz ettiği söylenebilir. Ancak uygulanan teşviklerin etkinliğinin ampirik olarak ölçümü yatırımlara ilişkin teşvik sistemi dışında pek çok etkenin de devreye girmesi sebebiyle oldukça zor olmaktadir.

Uluslararası piyasadan pay alabilmenin diğer bir şartı ülkelerin sahip oldukları teknoloji düzeyidir. Rekabetçi ve yenilikçi bir sanayiye sahip olabilmek için ülkelerin küresel rekabet ortamına uyumlu ve yüksek katma değerli ürünler üretebiliyor olmaları gerekmektedir. Türkiye'nin mevcut yapısı dikkate alındığında teknolojiyi üretmek yerine teknolojiyi tüketen bir yapı karşımıza çıkmaktadır. Ekonomik kalkınma ve uluslararası piyasalardan daha çok pay almanın yolu teknolojiyi üretmekten geçmektedir.

Teşvik politikaları, iktisat politikalarının bir aracı olarak değerlendirilmektedir. Teşvik sisteminin başarılı olabilmesi için ilgili teşvik araçlarının tespiti, araçların hangi alanlara yönelik olarak ne oranda ne kadar süreyle verileceğinin tespit edilmesi son derece önemlidir. $\mathrm{Bu}$ araçların etkileri izlenerek etkin olmayan araçlar yenileriyle değiştirilmelidir.

Yatıım teşvikleri; gerekliliği, fayda ve maliyetleri konusunda tartışmalara rağmen modern iktisadın yaklaşı iki yüz yıllık tarihi boyunca, iktisadi büyümenin ve kalkınmanın sağlanması noktasında önem arz eden unsurlardan birisi olmuştur. Yatırım teşvikleri, büyümenin yanı sıra istihdamın ve ihracatın artırılması, bölgeler arasındaki dengesizliklerin giderilmesi, uluslararası rekabet gücünün artırılması vb. amaçlarla, farklı gelişmişlik seviyelerindeki ülkelerin neredeyse tamamınca en çok başvurulan iktisat politikası araçlarından birisi olmuştur.

Sonuç olarak Türkiye'de uygulanan teşvik politikalarından ana hatları itibariyle yatırım hacminde artış ve ihracat düzeyinin artması ekseninde ekonomik büyüme ve istihdam başta olmak üzere makro değişkenlerde olumlu bir sonuç ortaya çıkarması beklenmektedir. Ancak uygulanan teşvik politikalarının pek çoğu arzu edilen başarıyı yakalayamamıştır. Bu noktada sektörel öncelikler ekseninde planlamaların yapılmasının daha önemli olduğu ön plana çıkmıştır. Özellikle son dönemlerde uygulamaya konan 
teşvikler, 2023 hedefleri doğrultusunda önemli bir dönüm noktası teşkil etmektedir. Bu bağlamda yatırım projelerinden beklenen gelir ve istihdam katkıları da somutlaştırılmış olarak ilgili programlarda kendine yer bulmuştur.

Teşviklerin ekonomik açıdan etkileri bağlamında literatürde çok sayıda uygulamalı çalışma yer almaktadır. Teşviklerin etkilerinin ele alındığı çalışmalarda tam anlamıyla bir fikir birliği sağlanabilmiş değildir. Bu çalışmada Türkiye'nin nüfus bakımından önemli bir kısmını barındıran 7 ile ait verilerden yola çıkarak 2012 yılında uygulamaya geçirilen yeni teşvik sisteminin istihdama etkisi incelenmeye çalışılmıştır.

Sonuç olarak kabul edilen teşvik başvurularıyla birlikte teşvikli yatırımlarda meydana gelecek artışların istihdam üzerinde olumlu etkisi olduğu sonucuna ulaşılmıştır. 7 il için gerçekleştirilen panel veri eş bütünleşme analizi sonuçlarına göre de teşvikli yatırımlar ile istihdam düzeyi arasında uzun dönemli bir ilişkinin var olduğu saptanmıştır.

\section{Kaynakça}

AKDEVE E. ve KARAGÖL E. T., (2013). Geçmişten Günümüze Türkiye'de Teşvikler ve Ülke Uygulamaları, Dumlupınar Üniversitesi Sosyal Bilimler Dergisi, (37), 341-342.

ALTUNKAYNAK, B., (2007). Sektörel Panel Veri Analizi Yaklaşımıyla Türkiye'nin AB Ükelerine İmalat Sanayi Bakımından İhracatının Belirlenmesi, Doktora Tezi, Gazi Üniversitesi Fen Bilimleri Enstitüsü, 122s.:15,26.

BALTAGI B.H., (1995). Econometric Analysis Of Panel Data, John Wiley and Sons, New York, 458p.:13.

BERBEROĞLUGIL, M. Melih (1994). Uygulanan Yatırım Teşvik Tedbirlerinin Etkinliği ve Uluslararası Kurumlar Açısından Değerlendirilmesi, Uzmanlık Tezi, Hazine ve Dış Ticaret Müsteşarlı̆̆ 1 , Ankara.

ÇíLOĞLU İ., (1997). Teşvik Sisteminin Değerlendirilmesi, Hazine Dergisi, 8(10).

DURMAN M., ve ÖNDER H., (2006). Sanayileşme Sürecinde Teşvikler, Alfa Aktüel Yayınları.

HSIAO C., (2003). Analysis of Panel Data, Cambridge, Newyork, 366p.: 18.

JAMES S., (2009). Incentives and Investments: Evidence and Policy Implications. World Bank. http://documents.worldbank.org/curated/en/945061468326374478/pdf/58816.

JENSEN NM Edmund M. ve MATTHEW W., (2015). Competing for Global Capital or Local Voters? The Politics of Business Location Incentives. Public Choice 164(3): 331-356.

THOMAS K.P., (2000). Competing for Capital: Europe and North America in a Global Era. Washington, DC: Georgetown University Press.

UĞUR, A., (2009). Hisse Senedi Getirilerinin Panel Veri Analizi ile Tahmini İstanbul Menkul Kıymetler Borsasında Bir İnceleme, Doktora tezi, İnönü Üniversitesi Sosyal Bilimler Enstitüsü, 266s.:57.

UNCTAD (2000). Tax Incentives and Foreign Direct Investment A Global Survey, ASIT Advisory Studies No.16, UNCTAD/ITE/IPC/Misc.3, Geneva. 